\title{
The Predictive Value of Positive Thinking and Attitudes of Secondary School Teachers Towards Education in Al-Madinah Al-Munawwarah
}

\author{
Fahad Mohammed Al-Muzaini \\ Educational Supervisor /Kingdom of Saudi Arabia \\ Prof. Dr. Rifa Rafie AL Zoubi \\ University of Jordan / Faculty of Educational Sciences
}

\begin{abstract}
The study aims to identify the predictive value of positive thinking and attitudes of secondary school teachers towards education in Al-Madinah Al-Munawwarah. To achieve the objectives of the study, the survey approach is used to suit its nature of this study, where a questionnaire is designed and distributed to a sample consisting of (360) teachers from Al-Madinah Al-Munawwarah city.The results of the study show that positive thinking for secondary school teachers towards education in Al-Madinah Al-Munawwarah for the study sample, in general, is of a low degree. The results also show that the attitudes of secondary school teachers towards education in AlMadinah Al-Munawwarah for the study sample, in general, is of a high degree. In the light of the results of the study, the researchers recommend working on holding training courses capable of increasing the contribution of secondary stage teachers in activating positive thinking for secondary school students in Al-Madinah AlMunawwarah and organizing professional development programs for teachers to be aware of the principles and elements of positive thinking and the methods for their development.
\end{abstract}

Keywords: predictive value, positive thinking, Secondary Schools, attitudes

DOI: $10.7176 / \mathrm{JEP} / 11-19-09$

Publication date:July $31^{\text {st }} 2020$

\section{Introduction}

The teacher plays the main role in achieving the educational objectives determined by any society for the sake of continuity to achieve comprehensive development. The teacher is one of the most central sources of students' experiences as he transfers his life and educational experiences to his students. With that, the importance of the teacher's experiences of his life is seen in his attitudes towards the teaching career and his positive thinking and its reflection on his practices in the classroom, which refine the student's personality and the success of the educational learning process.

The role of the teacher goes far beyond just teaching students, giving lectures and exams, and giving grades, so he takes on the roles of the organization, management, counseling, monitoring, and evaluation. The teacher plays an important role in influencing society through his role in achieving educational outcomes that suit the needs of society (Ulug, Ozden, and Eryilmaz, 2011).

Teacher's role is represented by the positive characteristics of teachers such as positive thinking, belief in education, self-organization, dedication, independence, and acceptance of guidance from others. With these features, the teacher becomes a mentor and a guide. Teacher's behavior is characterized by caring, kindness, acceptance of diversity, and sharing of responsibility, where employs high and effective communication skills that help him interact with others more confidently and positively (Ahmad et al., 2013)

Positive thinking is a mental attitude supporting positive thoughts and images that contribute to individual growth. It is also a mental attitude that carries high positive expectations and assumes positive results for each case. However, positive thinking means dealing with the challenges of life with a positive viewpoint, not necessarily by avoiding negative events but rather looking for the supreme benefit from potential negative situations to see the best in others on the one hand and his appreciation for himself on the other hand (Seligman and Csikszentmihalyi, 2014).

Positive thinking is also reflected in the individual's lifestyle and his attitude towards himself. The individual's sense of self and appreciation is one of the basic needs of the individual, and Maslow has included it in the highest degree of the basic needs in his pyramid because of its importance in determining the personality's style. Positive evaluation of the self has a clear impact on the number of personal positives of a person (Mcleod, 2007). Positive thinking leads to an increase in teacher's performance because students are attracted to teachers who exhibit more positive behavior. Certainly, teachers' influence on the mood of the classroom leads to better academic performance. Therefore, when selecting teachers, schools should give the highest importance to positive characteristics (Duckworth, Quinn, and Seligman, 2009).

And so, it is noted that positive teachers, with their positive attitudes towards education and students, succeed 
in overcoming work difficulties and problems facing them. Positive thinking is used in the usual mental processes to solve the problem, but it differs in the individual's attitude towards the problem, the expectations of success that the teacher sets as a result of solving the problem, and the beliefs held by the teacher about his ability to attain a successful solution. In detail, these beliefs make him focus on using effective methods and strategies in solving problems that face him because of his confidence in his abilities and capabilities (Salem, 2006). Meanwhile, teachers with negative thinking, as stated in Maurer (2012), are more likely to show weakness and withdrawal when facing adversities, believing that their efforts have little effect in overcoming difficulties.

The attitudes of the teacher towards his career have become one of the most interesting topics considering that the influence exercised by the teacher is due not only to the information he knows but also to his ability to guide and persuade students. Also, the teacher's personality plays an important role in the educational process as he cannot separate his psychological, social, and mental characteristics from his profession. Since the teacher's attitude towards education determines his behavior and emotions in educational situations, the teacher's attitudes toward education represent an important factor of good teacher's performance in the classroom and positive interaction with students, along with its positive reflection on students' academic performance and learning level (Abdulmutallab, 2014). Positive teacher's attitudes toward students and education lead to success while negative attitudes lead to failure. As a result, teacher responses and patterns of classroom management can contribute to shaping students' experiences, pieces of knowledge, and formation of positive or negative attitudes toward learning and self (Ulug, Ozden, and Eryilmaz, 2011).

Moreover, the positive attitudes of teachers towards education have positive effects on students' performance and the development of their personality. Negative attitudes harm both levels of performance and character development of students. This, in turn, indicates that the influence of teachers exceeds the boundaries of the classroom in the students' educational life, where their efficacy is clear throughout the student's entire life. Students take the teacher as role models while learning, which is why the behavior and attitudes of teachers, who spend most of the time with students, have an impact on the development of their personality. So, teachers should set a good example by interacting positively with students and showing positive behavior towards them such as asking questions that enhance their strengths, understanding their ideas, showing interest and appreciation, and increasing their motivation towards learning and success (Ulug, and Eryilmaz, 2011).

\section{Problem of the Study}

Through the researcher's practical experience as an educational training supervisor in the Education Department in the region of Al-Madinah Al-Munawwarah and the reality of dozens of field visits to schools, it is noted that the actual training need for teachers is the development of positive thinking and attitudes. Of note, the final report of the Educational Training Department in the Al-Madinah Al-Munawwarah Education Region for the academic year 2018/2019 shows that 702 teachers need a class management training program as the highest repetition of the nine training programs offered as a training need for teachers at a rate of 3 teachers in each school out of 234 schools whose training need for its teachers has been studied, or a percentage that makes up $12 \%$ of the target study population.

Having reviewed the previous studies, the researchers illustrate that some studies have dealt with positive thinking and attitudes towards education as Houla's study (2014) that has not shown any relationship between positive thinking and the attitude towards the profession, and Raqab's study (2006) that has shown a gap between the knowledge of positive thinking and its application in deciding by the faculty deans. However, other studies have focused on teachers in teacher preparation colleges as Daidan's study (2014), and other studies have related between attitudes toward education and classroom management patterns such as the study of Ajami (2007). As for the current study, it focuses on teachers in the secondary stage and explores the predictive ability of positive thinking and attitudes towards education. The current study is characterized by relating two main variables, positive thinking, and attitudes towards education, and it also examines teachers at the secondary level who are currently practicing the teaching process. Thus, the problem of the statement of this study is to identify the predictive value of positive thinking and attitudes of secondary school teachers towards education in Al-Madinah Al-Munawwarah.

Questions of the Study

In light of the problem of the study, the following questions are articulated.

1. What is the level of positive thinking for secondary school teachers in Al-Madinah Al-Munawwarah from the viewpoint of the teachers themselves?

2. What are the attitudes towards education for secondary school teachers in Al-Madinah Al-Munawwarah from the viewpoint of the teachers themselves?

\section{Objectives of the Study}

The following objectives are formatted to answer the questions of the study.

1. Explore the level of positive thinking for secondary school teachers in Al-Madinah Al-Munawwarah from the 
viewpoint of the teachers themselves.

2. Examine the attitudes towards education for secondary school teachers in Al-Madinah Al-Munawwarah from the viewpoint of the teachers themselves.

\section{Significance of the Study}

The significance of the study is articulated in the theoretical and practical areas. The theoretical significance of the study lies in examining the positive thinking and teacher attitudes towards education as it provides theoretical literature that helps those interested in this subject. It is also hoped that educational researchers will benefit from its educational results. Precisely, if a predictive value for positive thinking and teacher attitudes towards education is attained, this indicates the importance of positive thinking and its strategies for teachers and the need to prepare training programs to develop positive thinking and examine the reasons have led teachers to adopt certain attitudes according to the results of the study. Secondly, the practical significance lies in providing tools that have acceptable validity and reliability that can be used in later studies and conducting subsequent studies in light of the study results.

\section{Previous Studies}

Several studies have been done on the importance of the predictive value of positive thinking. Edmeads (2004) conducts a study aimed at identifying the relationship of some variables with the patterns of positive and negative thinking among university students. The study procedures are applied to a sample of (75) male students and (105) females in an American university and followed the descriptive correlational approach. The results of the study conclude that $(41.4 \%)$ of male and female students have shown a tendency towards positive thinking. The study also shows a fundamental relationship between the two patterns of thinking and the variables of achievement and gender for the benefit of male and female students with high achievement, where male and female students with high achievement show a greater tendency towards positive thinking. Finally, the study has not shown a fundamental relationship between the variable of specialization and the patterns of positive and negative thinking. Also,

Seligman (2004) conducts a study aimed at revealing the relationship between life satisfaction and various positive aspects of personality. The study's sample consists of (5299) adults between the ages of (35) to (40). The list of positive personality's strategies (VIA) published online in the English language is applied to the sample by Peterson, et al., (2002) and the life satisfaction measure by Dienar (1985). The study has followed a descriptive correlational approach. The results show a positive correlation between some aspects of positive thinking in the personality, which are gratitude, the ability to love, curiosity, forgiveness with oneself, appreciation of beauty and creativity, love of learning and wisdom, and satisfaction with life. Moreover, the results show statistically significant differences in life satisfaction attributed to positive aspects of the personality such as gratitude, the ability to love and forgiveness with oneself compared to other positive aspects such as appreciation of beauty, love of learning, creativity, and wisdom.

Robinson and Blackburn (2008) conduct a study aimed at investigating the relationship between teachers' self-efficacy and job satisfaction. The study sample consists of (80) male and female teachers who answered the self-efficacy scale (Woolfolk and Moran-Tschannen, 2001) which includes three dimensions: student participation, educational practices, and classroom management. The study has followed the descriptive correlational approach. The results show a relationship between subjective efficacy and a sense of job satisfaction, and the absence of differences in the subjective effects of teachers according to the variable of experience, and that male teachers have more subjectivity than female teachers.

In his 2013 study, Pickens explores school teachers' perceptions about the extent of their principals' behavioral leadership and its effect on improving basic schools in the suburbs. The study is conducted in an area where students suffer from low academic achievement and followed the descriptive-survey approach. Data is collected from (21) teachers from different majors and the principal of the school. The qualitative data collected through the interview, review of documents, and data collected from field notes are analyzed. The results of the analysis of these data show that the administrative behavior of the school director directly affects the teachers and spontaneously affects students' achievement and the improvement of the level of the academic school in particular. In their 2018 study, Shammari and Quraishi identify the effect of Wohn and Phelps strategy on positive thinking among fifth-grade primary students Science Course using the experimental approach to achieve the study's objectives. The study population consists of 52 fifth-grade primary students at Al-Warka School in the city of Kut, Iraq. The study sample is divided into two experimental and control groups. The study shows that there are no differences between students of the experimental and control group on the scale of positive thinking.

In light of the previous studies, it is noted that the previous studies have been used to direct the current study towards the optimal way in selecting a data collection and analysis instrument using the appropriate statistical methods and processing. The most important thing that distinguishes this study from the previous relevant studies is that it examines the predictive value of positive thinking and the attitudes of secondary school teachers towards 
education in Al-Madinah Al-Munawwarah.

\section{Term of the Study}

To attain its objectives, the current study adopts the following terms:

Positive thinking: It is defined as self-motivating fuel to do business by taking advantage of the capabilities of the individual (Onji, 2013). Procedurally, it is the degree obtained by the teacher on a standardized scale of preparation developed by the researcher.

Attitudes towards education: It is defined as an acquired and learned willingness, and it is a relationship between the individual and a subject of the environment that has multiple emotional characteristics that represent a degree of consistency and agreement. The direction can be specific or general/positive or negative (Amasha, 2010). Procedurally, it is characterized by subjectivity more than objectivity as it is the degree that the teacher gets on the scale developed by the researcher.

\section{Methodology of the Study}

This study aims to examine the predictive value of positive thinking and attitudes of secondary school teachers towards education in Al-Madinah Al-Munawwarah. Thus, it uses the survey approach.

\section{Study Population}

The study population consists of all secondary school teachers in Al-Madinah Al-Munawwarah.

\section{Study Sample}

As for the study sample, it is selected according to the random sample method, which gives each individual in the study population equal opportunities. The number of the sample population is (360) male and female teachers from secondary school teachers in Al-Madinah Al-Munawwarah, and Table (1) illustrates this.

Table 1: Frequencies and Percentages According to the Study Variables

\begin{tabular}{|l|l|l|l|}
\hline \multirow{2}{*}{ Gender } & Categories & Frequencies & Percentage \\
\hline \multirow{2}{*}{$\begin{array}{l}\text { Academic } \\
\text { Qualification }\end{array}$} & Male & 245 & .68 \\
\cline { 2 - 4 } & Female & 276 & .32 \\
\hline & Bachelor Degree & 278 & .77 \\
\cline { 2 - 4 } & Graduate Studies & 82 & .33 \\
\hline
\end{tabular}

\section{Study Instrument}

To achieve the objectives of the study, the theoretical literature and previous studies addressing the positive thinking and attitudes as a Picken's study (2013), Edmeads's study (2004), and other related studies are reviewed.

\section{Instrument's Validity}

To verify the validity of the content of the study instrument, the content is presented to a group of experts and specialists in Jordanian universities to express their views in the questionnaire items in terms of clarity of meaning, linguistic construction, and the degree of suitability for the field to which it belongs, and any other appropriate modifications and notes. $(80 \%)$ of the validators' comments are taken into consideration to achieve the objectives of the study.

\section{Instrument's Reliability}

To ensure the reliability of the study instrument, it is checked through the test-retest method, along with calculating the internal consistency coefficient according to the Cronbach alpha equation. Table (2) shows the internal consistency coefficient according to the Cronbach alpha equation and the test-retest reliability for the fields and the instrument as a whole and these values are considered appropriate for this study.

Table 2: The Internal Consistency Coefficient of Cronbach Alpha and the Test-Retest Reliability of the Domains and the Total Score

\begin{tabular}{|l|l|l|}
\hline Questionnaire & Test-Retest & Internal Consistency \\
\hline Positive thinking towards education & 0.85 & 0.72 \\
\hline Attitudes of teachers towards education & 0.91 & 0.73 \\
\hline Total scores & 0.88 & \\
\hline
\end{tabular}

The criterion for calculating the means of the study instrument is determined by dividing it into three degrees: low, medium, and high, according to the following formula:

Category length $=$ Highest value of the substitute - the lowest value of the substitute / Number of levels

$$
1.33=3 /(1-5)=
$$


Accordingly, the following criterion is used to judge the responses of the study sample:

The low score is less than 2.33 .

The medium score is from 2.34 to 3.67 .

The high score is from 3.68 to 5.00 .

\section{Results and Discussion}

The discussion and results related to the questions of the study are as follow:

1. What is the level of positive thinking for secondary school teachers in Al-Madinah Al-Munawwarah from the viewpoint of the teachers themselves?

To answer this question, arithmetic means and standard deviations are calculated as shown in Table (3).

Table 3 :Arithmetic Means and Standard Deviations for the Level of Positive Thinking for Secondary School Teachers in Al-Madinah Al-Munawwarah from the Teachers' Point of View Themselves in Descending Order According to the Arithmetic Mean

\begin{tabular}{|l|l|l|c|c|c|}
\hline Rank & No & Items & AM & SD & Degree \\
\hline 1 & 11 & I sympathize with others about their problems & 2.96 & .20 & Medium \\
\hline 2 & 17 & I think the future will be better than the present & 2.93 & .26 & Medium \\
\hline 2 & 14 & I think life is beautiful and deserves to enjoy every moment of it & 2.93 & .31 & Medium \\
\hline 4 & 20 & I try to secure my future through my hard work & 2.75 & .53 & Medium \\
\hline 4 & 18 & My belief in God dispels any fear I have from the future & 2.70 & .49 & Medium \\
\hline 6 & 13 & I respect the right of others to everything & 2.66 & .58 & Medium \\
\hline 7 & 16 & I think everyone has the right to live a safe and well-off life & 2.65 & .51 & Medium \\
\hline 7 & 3 & I do what I think is true & 2.65 & .58 & Medium \\
\hline 9 & 4 & I trust what I do in my life & 2.55 & .50 & Medium \\
\hline 10 & 2 & I am satisfied with my life & 2.51 & .56 & Medium \\
\hline 11 & 15 & There are safe and beautiful places in this world that I wish to visit & 2.31 & .73 & Low \\
\hline 12 & 6 & I am always self-developing for the better & 1.87 & .65 & Low \\
\hline 13 & 5 & I feel that I am doing my job well & 1.82 & .66 & Low \\
\hline 14 & 12 & I love teamwork & 1.79 & .67 & Low \\
\hline 15 & 21 & $\begin{array}{l}\text { I have the ability to overcome the tragedies that I have experienced } \\
\text { in the past so that I can live well }\end{array}$ & 1.58 & .65 & Low \\
\hline 16 & 8 & I am able to meet my needs & 1.54 & .61 & Low \\
\hline 17 & 19 & $\begin{array}{l}\text { I see good planning helps me achieve my ambition at work and } \\
\text { anything in life }\end{array}$ & 1.52 & .70 & Low \\
\hline 18 & 9 & I pinpoint the things I love and don't like exactly & 1.51 & .56 & Low \\
\hline 19 & 7 & I feel the same when I achieve a goal in my life & 1.48 & .65 & Low \\
\hline 20 & 1 & I am satisfied with my potential & 1.45 & .58 & Low \\
\hline 21 & 10 & I forgive others who have sinned against me & 2.16 & .52 & Low \\
\hline $\begin{array}{l}\text { Total } \\
\text { domain }\end{array}$ & the & Positive thinking & Low & \\
\hline
\end{tabular}

Table (3) shows that the arithmetic mean of the items has ranged (1.31-2.96) where the item (11) stating "I sympathize with others in their problems", ranks in the first place with an arithmetic mean of (2.96) and with a medium degree. Then, the two items (17 and 14) state "I think the future will be better than the present" and "I think life is beautiful and deserves to enjoy every moment of it" rank in the second place and with a mean of (2.93). Next, item (10) states "I forgive others who sinned against me" ranks in the last place and with a mean of (1.31). The mean of positive thinking for teachers as a whole is (2.16). This may also be due to the awareness of the study sample's members of the nucleus of cognitive competence and the effectiveness of dealing with life's problems and challenges and overcoming their adversity and hardship and it is not just a method or a systematic approach but rather an attitude that energizes energies and generate the present and potential capabilities for work. It also constitutes a successful treatment for maintaining morale and psychological well-being, as ideas determine the emotional mood and state. Through the analysis of ideas, it is possible to reveal the implicit ideas that cause negative emotions and analyze them to show what distortions are included in the objective and subjective reality, and when the ideas change in a more positive or realistic direction, the emotional state also adjusts positively.

This may also be due to the realization of the study sample's members that positive thinking makes life enjoyable and full of happiness with anxiety but to a lesser extent. It is a path of creativity and success, as it helps the individual to move from one stage to another through realistic patterns and scientific methods that develop self-confidence, which is one of the most important foundations that help individuals succeed and be creative at all levels. 
2. What are the attitudes towards education for secondary school teachers in Al-Madinah AlMunawwarah from the viewpoint of the teachers themselves?

To answer this question, arithmetic means and standard deviations are calculated as shown in Table (4).

Table 4: Arithmetic Means and Standard Deviations for the Level of Attitudes Towards Education for Secondary School Teachers in Al-Madinah Al-Munawwarah from the Teachers' Point of View Themselves in Descending Order According to the Arithmetic Mean

\begin{tabular}{|c|c|c|c|c|c|}
\hline Rank & No & Items & AM & SD & Degree \\
\hline 1 & 1 & $\begin{array}{l}\text { I think education is the best investment in the abilities and } \\
\text { capabilities of the people of the homeland }\end{array}$ & 4.72 & .48 & High \\
\hline 2 & 5 & My profession provides the necessary job safety & 4.64 & .78 & High \\
\hline 3 & 26 & $\begin{array}{l}\text { The teacher does not end his role in school education, but extends to } \\
\text { all members of society }\end{array}$ & 4.63 & .51 & High \\
\hline 4 & 27 & $\begin{array}{l}\text { The school administration is interested in working with one team } \\
\text { spirit }\end{array}$ & 4.56 & .50 & High \\
\hline 5 & 28 & I think I can help every student reach their full potential & 4.55 & .58 & High \\
\hline 6 & 9 & Investing waiting classes in my students' education & 4.49 & .63 & High \\
\hline 7 & 2 & I have a friendship with some of my schoolmates & 4.42 & .77 & High \\
\hline 7 & 6 & $\begin{array}{l}\text { I share new knowledge and information that I learn with my } \\
\text { colleagues }\end{array}$ & 4.42 & .81 & High \\
\hline 9 & 22 & $\begin{array}{l}\text { I collaborate with the Student Adviser to help students modify their } \\
\text { behavior, which hinders the course of the lesson }\end{array}$ & 4.35 & .79 & High \\
\hline 10 & 31 & I give active community awareness & 4.30 & .80 & High \\
\hline 11 & 30 & $\begin{array}{l}\text { I read a lot in the modern teaching strategies that suit the subjects I } \\
\text { study }\end{array}$ & 4.27 & .76 & High \\
\hline 12 & 20 & I offer voluntary hours to spread the message of education & 4.17 & .70 & High \\
\hline 13 & 4 & If one of my colleagues is absent, I rush to check on him or her & 4.15 & .97 & High \\
\hline 14 & 32 & $\begin{array}{l}\text { Social media: Twitter, Facebook and WhatsApp are used to raise } \\
\text { awareness of education topics }\end{array}$ & 4.14 & .88 & High \\
\hline 15 & 29 & I follow the community news and participate in important events & 4.14 & .85 & High \\
\hline 16 & 17 & My discussions with my colleagues are based on positive dialogue & 4.10 & .99 & High \\
\hline 17 & 18 & I participate in neighborhood clubs in my district & 4.04 & .95 & High \\
\hline 18 & 10 & I urge my students to participate in voluntary work & 4.03 & 1.3 & High \\
\hline 19 & 3 & $\begin{array}{l}\text { I participate in procedural research experimenting with modern } \\
\text { methods of teaching }\end{array}$ & 4.01 & 1.13 & High \\
\hline 20 & 14 & The school leader gives me the support I need & 3.99 & 1.10 & High \\
\hline 21 & 15 & $\begin{array}{l}\text { Continuous professional development is one of the most prominent } \\
\text { characteristics of teachers }\end{array}$ & 3.97 & 1.00 & High \\
\hline 22 & 12 & I actively participate in school activities & 3.96 & 1.048 & High \\
\hline 23 & 7 & I always strive for self-development in the field of teaching & 3.94 & .98 & High \\
\hline 24 & 16 & Together with my colleagues, I form teams & 3.93 & 1.05 & High \\
\hline 25 & 13 & I make sure to read books in my major & 3.93 & 1.18 & High \\
\hline 26 & 24 & I give up sick leave if I feel it will affect the interest of my students & 3.90 & .90 & High \\
\hline 27 & 21 & $\begin{array}{l}\text { I remain loving to my students even if they deviate from the class } \\
\text { system }\end{array}$ & 3.89 & .84 & High \\
\hline 28 & 23 & $\begin{array}{l}\text { Working with students gives me an opportunity to instill values and } \\
\text { build ethics in them }\end{array}$ & 3.55 & 1.24 & Medium \\
\hline 29 & 8 & The school administration maintains my rights & 3.48 & 1.13 & Medium \\
\hline 30 & 25 & I listen to views and suggestions of the school leader & 3.38 & 1.03 & Medium \\
\hline 31 & 11 & I participate in the evaluation and development of courses & 2.91 & 1.40 & Medium \\
\hline 32 & 19 & $\begin{array}{l}\text { The school administration exercises the principle of fairness in } \\
\text { treatment }\end{array}$ & 2.65 & 1.18 & Medium \\
\hline \multicolumn{2}{|c|}{$\begin{array}{l}\text { Total for the } \\
\text { domain }\end{array}$} & Attitudes & 4.00 & .48 & High \\
\hline
\end{tabular}

Table (3) shows that the arithmetic means for the items have ranged (2.65-4.72), where the item (1) which states "I think education is the best investment in the abilities and capabilities of the people of the homeland", ranks in the first place with an arithmetic mean of (4.72) and a high degree. Then, item (5) which states "My profession provides the necessary job safety" ranks in the second place with a mean of 4.65, while item (19) which 
states "School administration exercises the principle of fairness in treatment" ranks in the last place with a mean of (2.65). The mean of teachers 'attitudes towards education as a whole is 4.00 . This may be due to the awareness of the study sample's members that the teacher is the main pillar for achieving the quality of the educational system because of the importance of his role in the continuous improvement of the level of students, which represents the goal that any educational system seeks. Also, whatever the case of the school, the density of classrooms in it, the nature of the curricula, the quality of technology and learning resources, and the elements of the learning environment, they are considered untapped if no teacher can employ them effectively. The teacher and the teaching profession go hand in hand, if there is a competent teacher, there will be a positive attitude towards the profession and the students' learning process. This is due to the teacher's awareness that the positive attitudes towards the teaching profession have a great impact in raising the level of the education process, due to the motivation and love that these positive attitudes provide to the educational process, which is reflected in the teacher's performance and efficacy within the class. The teacher's positive and negative attitudes have clear implications for students' motivation towards learning, the school subject, participation in-class activities, and interaction with teacher's attitudes.

\section{Recommendations}

In light of the results, the study recommends the following:

- several recommendations have been made such as holding training courses capable of increasing the contribution of secondary school teachers in activating positive thinking among secondary school students in Al-Madinah Al-Munawwarah,

- $\quad$ organizing professional development programs for teachers to inform them of the principles and elements of positive thinking and the techniques for developing them

- conducting future studies that address the role of universities in developing positive thinking from the viewpoint of faculty and teachers among students.

\section{References}

\subsection{References in Arabic}

Salem,Amani.(2006). Efficacy of a program to develop positive thinking among students exposed to psychological stress in light of the cognitive model. Journal of the College of Education in Ismailia, 4(4) 105-69.

Shammari, Muhammad and Al-Quraishi, Russell. (2018). The effect of Wohn, Phelps' strategy on fifth-grade primary school students. Lark's Philosophy, Linguistics and Social Sciences, 3 (31) 125-147.

Daidan, Hamidi. (2014). Positive thinking and its relationship with communication skills among students of the preparatory year deanship at King Saud University in Riyadh. Education Journal, 161 (3) 521-82.

Abdul-Muttalib, Abdul-Muttalib. (2014). Attitudes towards the teaching profession and its relationship to psychological alienation and academic achievement among a sample of students from the College of Basic Education in Kuwait. Journal of Gulf and Arabian Peninsula Studies, 40 (155) 51-105.

Ajami, Ali. (2007). The prevalent classroom management patterns in middle schools in the State of Kuwait and their relationship to teachers' attitudes towards the teaching profession, unpublished Master Thesis. Amman Arab University, Jordan.

Ahmad, I \& Hamdan, S \& Alam, Z and Khalil, R. (2013). Effects of professional attitude of teachers on their teaching performance: Case of government secondary school teachers in 3 Malakand Region, Khyber Pakhtunkhwa, Pakistan 4. Journal of Educational and Social Research, 3(1) 1-16.

Duckworth, A \& Patrick D, and Martin, E. (2009). Positive predictors of teacher effectiveness. The Journal of Positive Psychology, 4(6) 540-47.

Maurer, A . (2012). The Impact of positive traits on teacher performance within systems are driven charter school. Management Organization, 5(8) 34-65>

\subsection{References in English}

Onji, K. (2013). Estimating the effects of procrastination on performance: A small sample study. The Journal of Socio-Economics, 2(44) 85-90.

Pickens, S .J. (2013). Teachers' Perspectives of leadership behavior that facilitate school improvement. DAI- $A, 75$ (04) 23-36.

Seligman, M and Mihaly, C. (2014). Positive psychology: An introduction. In Flow and the Foundations of Positive Psychology, Dordrecht: Springer Netherlands, 5(8) 279-98.

Seligman., M., Peteson, C. \& Park .(2004). Strengths of character and well being. Journal of Social and Clinical Psychology, (23) 603-619

Ulug, M and Melis, S and Ahu, E. (2011). The Effects of Teachers' Attitudes on Students' Personality and Performance. Procedia-Social and Behavioral Sciences, 2 (30) 738-42. 